\title{
Rheological Analysis of Bulging of Continuously Cast Slabs with Elementary Bending Theory
}

Kōhei Fukawa, Hiromi Matsumoto, and Kōe Nakajima

\begin{abstract}
Synopsis:
The bulging of the shell in continuously cast steel slabs between the retaining rolls has been computed in terms of elementary bending theory. Creep and elasto-plasticity are taken into account at the same time as the factors influencing the bulging. The calculated results are as follows:

i) Bulging pattern comprises concave zone around the exit and convex zone near the inlet of a retaining roll.

ii) The depth of the above mentioned wave is larger than that of conventional bulging as measured at the middle of the roll span.

iii) The bulging calculated by the present study depends sensibly on the parameters for the stressstrain relationship of the material.
\end{abstract}

\section{1. 緒}

言

鋼の連続鋳造法は, 従来の造塊一分塊法にくらべて, 歩 留りの问上, 省エネルギー, 省力化などの長所をもつて いるので, 1970 年代に飛躍的に拡大した.

連続鋳造鋳片は凝固するまでの間に，熱忍力，溶鋼静 压，ロールとの機械的相互作用などにより变形を受け る、スラブ鋳师におては，その広い面にいわゆるバル ジングが，しばしば観察される。 この現象はシェルに作 用する溶鋼静圧により生ずる。このバルジングは，スラ

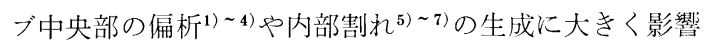
していると考えられている.

連続鋳造の保持ロールの間隔は $30 \mathrm{~cm} \sim 45 \mathrm{~cm}$ であ り, 高温多湿の悪条件下, ロール間のシェルの形状の詳 細な測定は必ずしもなされていない8) 11).

一万バルジングを計算するモデルは幾つか出されてい る. 弾性によるもの ${ }^{12)}$ や弾性塑性によるもの7)13)14) であ る. 藤井ら ${ }^{6)}$ や PALMAers and ETIENNE ${ }^{15)}$ はクリープに よる変形を計算しているが，スラブは静止と仮定してい る. Miyazawa and Schwerdtfeger ${ }^{16)}$ は動的状態に おけるロール間のスラブのバルジングを，クリープと弾 塑性とに分けて計算しているが，この 2 つの要因の結柆 は重畳できないものであり，彼らも述べているように，
また Miyazawa and SchwerdtFegeR ${ }^{16)}$ の計算の境界 条件は動的連続条件をみたして扣らず，また加工硬化に 対する歪みの基準点を考元ている区間の口ールの直下に とつていることも疑問である.

本研究に执いては，鋳片のロール間におけるバルジン グを, クリープ変形と弾塑性変化とを同時に考虑したも デルにより, 動的連続の条件のもとで解析した. ロール 間隔にくらべて，スラブの幅は十分広いとして，従来の 論文と同様に二次元曲げ理論を用いた.

本研究の目的は, 高温材料のレオロジカルな特性值と 変形形状との関連を明らかにするにある.

\section{2. バルジング変形の解析方法}

\section{$2 \cdot 1$ 解析モデルと方程式}

バルジングは Fig. 1 に示すように，鋳片内部の未凝 固部に生ずる溶鋼静压 $p$ によて凝固シェルが膨れる現 象であつて，本来 2 軸方向であるが，スラブ幅を $2 \mathrm{~m}$ と すると, ロール間隔とスラブ幅の比は $1 / 4 \sim 1 / 7$ と小さ いため, これを Fig. 1 に示すよらな一軸バルジングと みなすことが出来る。またバルジングが問題となる曲げ 戻し点前後では高度差の影響を無視して溶鋼静圧を一定 とし，また対象区間での凝固によるシェル厚増加は無視 するものとする.

上方のシェルのみを考えると， シェルにかかる力は クリープと弾塑性を同時に考慮したモデルが望ましい.

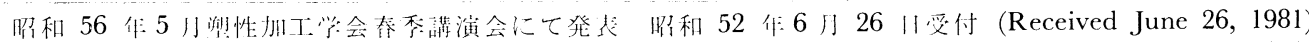

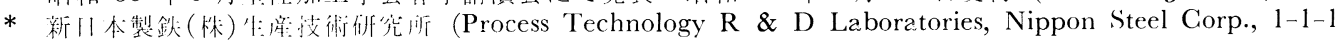

Edamitsu Yawatahigashi-ku Kitakyushu 805)

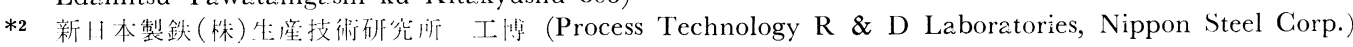




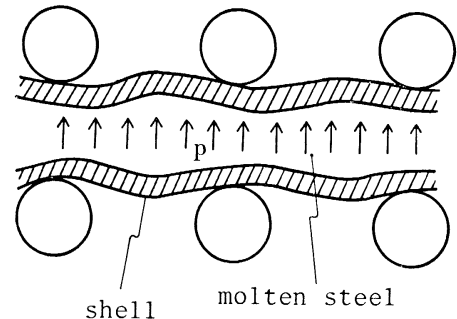

Fig. 1. Schematic of bulging.

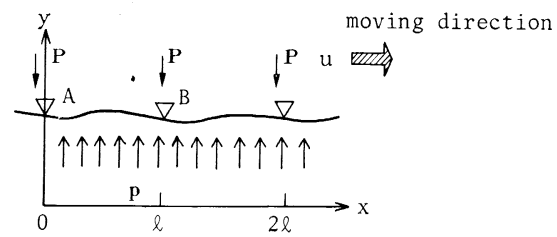

Fig. 2. Model for bulging analysis.

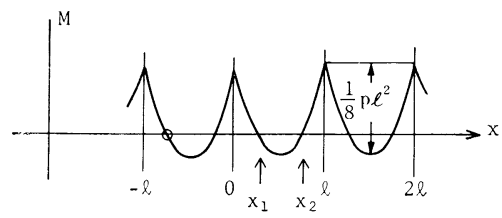

Fig. 3. Moment distribution between rolls.

Fig. 2 に示すように，溶鋼静圧 $p$ とロールから受ける 反力Pだけである.

ロール間隔 $l$ が一定である場合を考えると，定常状態 ではほぼ平行対称性が成立し, 変形の解は周期 $l$ の周期 関数になる.これより， $0 \leq x \leq l$ 内でのモーメント $M$ (x) は $M(x)=\frac{p}{2}\left(x-\frac{l}{2}\right)^{2}-A$

で表せる、ここでxはロールとシェルとの接触点（一般 にはロール直下よりわずかにずれる）を起点に測つた長 さ方向の座標，A は未知の常数である。この様子を Fig. 3 に示す。図中にモーメントが 0 となる点 $x_{1}, x_{2}$, では，変形が停滞する，連鋳機における鋳片表面温度は $800 \sim 1200^{\circ} \mathrm{G}$ であり，また鋳造速度は $0.5 \sim 2.0 \mathrm{~m} /$ minである.このように高温低速の現象であるため, こ のように変形が停滞する点で, 以前の歪み履歴の影響は 消隇すると仮定する。したがつて, シェル内の応力 $\sigma$

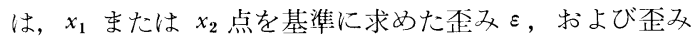
速度实を用いて

$$
\left\{\begin{array}{r}
\sigma= \pm \sigma_{0} \varepsilon^{\alpha} \dot{\varepsilon}^{\beta} \phi(T) \quad(T \text { は絶対温度 }) \\
\phi(T)=\exp \left[T_{0}\left(\begin{array}{cc}
1 & 1 \\
T & 1
\end{array}\right)\right](\alpha, \beta, \cdots \cdots \\
\left.\sigma_{0}, T_{0} \text { は常数 }\right)
\end{array}\right.
$$

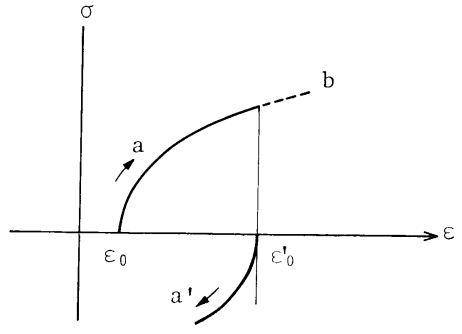

Fig. 4. Relation between stress and strain.

で与えられるとする。

この様子を Fig. 4 に示す。すなわち，ある基準状態 $\varepsilon_{0}$ から $\varepsilon_{0}{ }^{\prime}$ まで変形を加えた後, 逆方向に変形する 之, 図のように $\varepsilon_{0}$ から始まる曲線 $\mathrm{a}$ と $\varepsilon_{\mathbf{0}}{ }^{\prime}$ から始まる 曲線 $a^{\prime}$ とは同じ形であるとする。

シェルの曲がり曲率を $K$ とし，さらに $x_{1}$ または $x_{2}$ 点からの曲率の増分を $\Delta K$ とすると, 厚さ方向各場所 $\eta$ (外面で 0 , 内面で $S$ とる) にお汁る歪及拈よび歪速 度は

$$
\left\{\begin{array}{l}
\varepsilon(\eta)=\Delta K \cdot\left(\eta-\eta_{0}\right) \\
\dot{\varepsilon}(\eta)=\Delta \dot{K} \cdot\left(\eta-\eta_{0}\right)
\end{array}\right.
$$

と表される.（定数 $n_{0}$ は全張力が 0 という条件から決 まる.）応力 $\sigma$ は

$$
\sigma(n)= \pm \sigma_{0} \Delta K^{\alpha} \cdot \Delta K^{\beta} \cdot\left(\eta-\eta_{\mathbf{0}}\right)^{\alpha+\beta} \cdot \varphi(T)
$$

となる。またモーメントと曲率の関係式は

$$
\Delta \dot{K}=\dot{K}=u \cdot \stackrel{d\lrcorner k}{d x} \quad(u \text { は鋳造速度 })
$$

を考慮すると(4)より

$$
M=\Theta \cdot \Delta K^{\alpha}\left(\begin{array}{c}
d \Delta k \\
d x
\end{array}\right)^{\beta}
$$

で表される.ここで

$$
\Theta=u^{\beta} \int_{0}^{\mathrm{s}} \sigma_{0} \cdot\left(\eta-\eta_{0}\right)^{\alpha+\beta+1} \cdot \phi(T) d \eta
$$

はシェル内温度分布とシェル厚の影響を示す常数であ る. 平行対称性の条件は

$$
\left\{\begin{array}{l}
K(0)=K(l) \\
\int_{0}^{e} K(\xi) d \xi=0
\end{array}\right.
$$

で与えられる.

\section{$2 \cdot 2$ 方程式の規格化と相似法則}

座標 $x$ およびクをそれぞれ $l$ および $S$ で規格化する. $x=l \bar{x}, \eta=S \bar{\eta}(0 \leq \bar{x} \leq 1,0 \leq \eta \leq 1)$ モーメントは $p l^{2}$ で規格化し， $M=p l^{2} M(\mathrm{~N} 2)$ とする と, (1) 式は

$$
M=\frac{1}{2}\left(\bar{x}-\frac{1}{2}\right)^{2}-\frac{1}{2} a^{2}(a \text { は常数 })
$$


さらに曲率 $K$ を $\left.K_{0}=\left(p l^{\alpha+\beta} / \Theta\right)\right)^{1}+\beta$ で規格化し， $K=$ $K_{0} \cdot K$, および $\Delta K=K_{0} \Delta K(\mathrm{~N} 3)$ とすると (5) 式は次の ように規格化される.

$$
M=\Delta K^{\alpha}\left(\frac{d \Delta K}{\alpha \bar{x}}\right)^{\beta}
$$

(6) 式からは直ちに次の形が導かれる.

$$
K(0)=\bar{K}(1) \text { および } \int_{0}^{1} K(\xi) d \xi=0
$$

(E1)〜 (E3) によつて方程式系が完成するが，これら に含まれるパラメータは $\alpha, \beta$ のみである。したがつ $\tau, \alpha, \beta$ 以外の条件は変形パターンに無関係であり, 単に変形の大きさが変わるだけであると言う相似法則が 得られる.

\section{$2 \cdot 3$ 方程式の解法}

方程式 (E1)～(E3) は常微分方程式であり, 正確な解 を求めるには数值計算によらねばならない. 解法の手順 は次のと拈りである。(以下バーは省略)

(1)未知数 $a$ を仮定して変形の停滞点 $x_{1}, x_{2}(=1 / 2 \mp a)$ を求める.

(2) $x_{1}$ 点を基準にして (E2) を解き， $x_{1} \leq x \leq x_{2}$ での $\Delta k$ の解 $\Delta K_{\mathrm{I}}(x)$ を求める.

$\left(\Delta K_{\mathrm{I}}\left(x_{1}\right)=0\right.$ を初期值とする・ $)$

(3) $x_{2}$ 点を起点として, 同様に（E2）を解さ $x_{2} \leq x \leq$ および $0 \leq x \leq x_{1}$ での $\Delta K$ の解 $\Delta K_{\mathrm{II}}(x)$ を求める.

(E 3), より $\left.\Delta K_{\mathrm{II}}(0)=\Delta K_{\mathrm{II}}(1)\right)$

(4)上に求めた解が矛盾しないためには, $\Delta K_{1}\left(x_{2}\right)+$ $\Delta K_{\mathrm{II}}\left(x_{1}\right)=0$ であることが必要であるが，一般には満足 されない.このため Newton 法によつてaの值を修正 し，収束するまで(1)〜(4)を繰り返す.

(5) $(\mathrm{E} 3)_{2}$ の条件を用いて, $K_{1}=K\left(x_{1}\right), K_{2}=K\left(x_{2}\right)$ を 求める.

(6)一般点の曲率 $K(x)$ は

$$
K(x)=K_{1}+\Delta K_{\mathrm{I}}(x) \quad\left(x_{1} \leq x \leq x_{2}\right)
$$

および

$$
K(x)=K_{2}+\Delta K_{\text {II }}(\mathrm{x}) \quad\left(x_{2} \leq x \leq 1 \text { または } 0 \leq x \leq x_{1}\right)
$$

で求められる. 曲率 $K(x)$ を積分して変形形状 $y(x)$ を 求める.

\section{3. 解 析 結 果}

\section{$3 \cdot 1$ 変形パターンの特徴}

Fig. 5 に $\alpha=0.3, \beta=0.3$ の塨介に規格化方程式を 解いた結果を示す（ $\alpha$ は，より大きな歪みの場合の変 形抵抗值 ${ }^{17)}$ 上り外插して求めたもののほぼ中央健, $\beta$ は クリープ特性值 ${ }^{18) 19115)}$ のほぼ中央值を採用した・）この 解には次のような特徵がある.

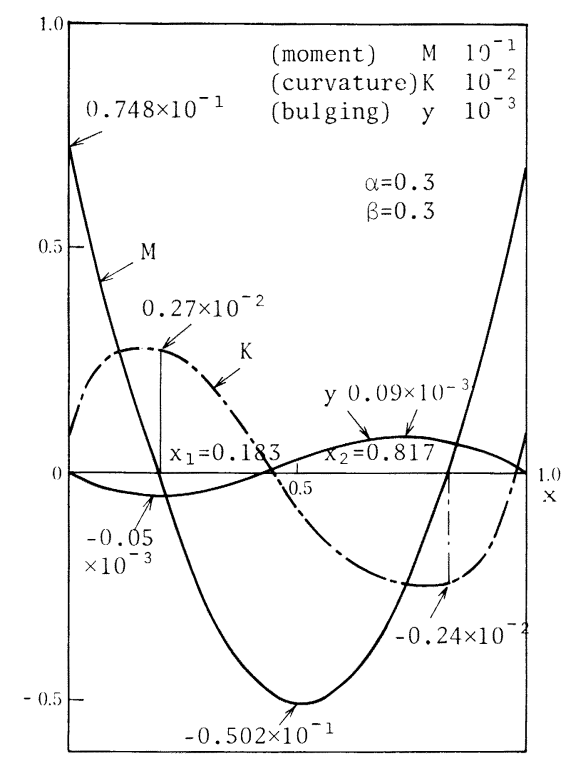

Fig. 5. A result of bulging analysis. (normalized) $(\alpha=0.3$ and $\beta=0.3)$

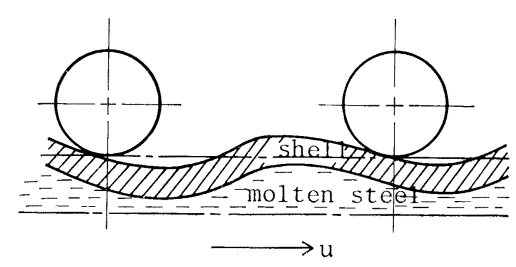

Fig. 6. Schematic of bulging.

（1）鋳师表面はロールを出た值後は一度内側に入り 込むが，溶鋼静圧によつて徐々に外側に曲げ出され，次 のロールによつて再び内面に押しつけられる.

(2)この時, 内面側への入り込文量之, 外面側への 曲げ出し量を比べると，曲げ出し量の方が大きい.

(3) 凝固シェル内面に引つぱり応力が作用するの は, ロール直前から直後にかけての領域 $\left(x_{2} \rightarrow 1,0 \rightarrow x_{1}\right)$ であり，ロール間隔の半分より狭い.

（4）曲げの進行方向が逆転する基準点 $\left(x_{1}\right.$ および $\left.x_{2}\right)$ の近くでは，ほとんど変形が進行しない.

バルジング形状を模式的に画くと Fig. 6 となる. シ エルとロールの接触点はロール淔下よりも若下上流側に 移動するが，ロール間䊖中心点が必ずしもバルジングの 最大の点となるのではなく，また測定䈏所によつては口

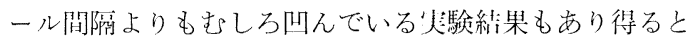
予想される. 前述のごとくシェル形状の詳細測定は行わ れていないので，この予測を奏証するデータはない，笑 


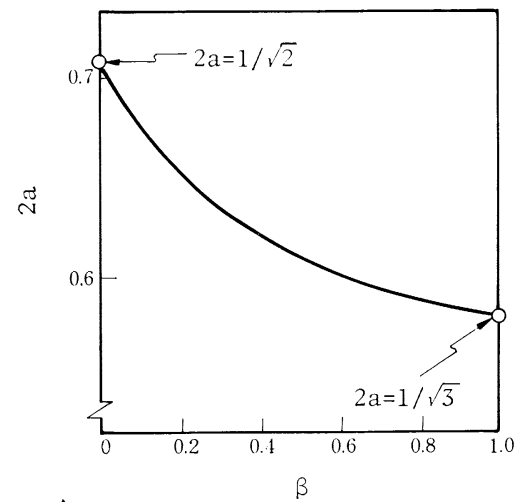

Fig. 7. Relation between $\beta$ and $2 a$

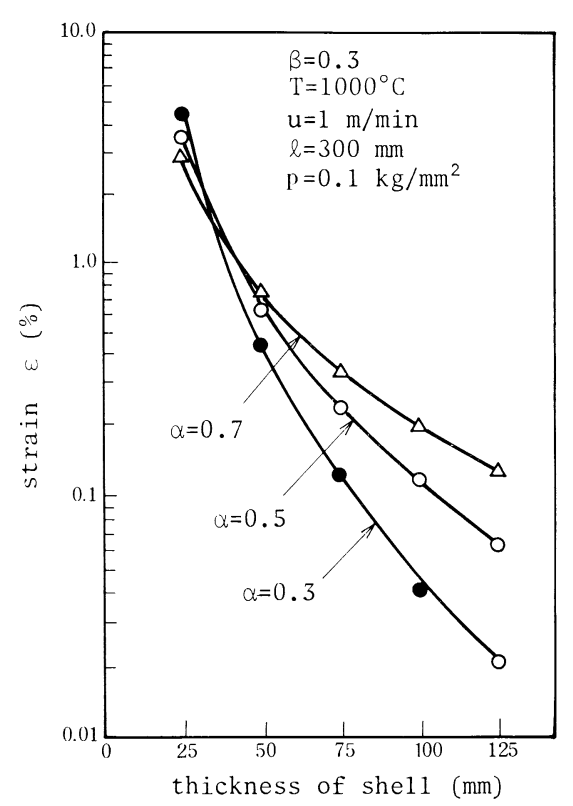

Fig. 8. Relation between thickness of shell and strain.

際の連鋳機では測定困難である. 鋳片·厚又に対してロー ル径の小さいモデルを作机ば，このシェル変形の詳細測 定が可能と考える.

材質常数 $\alpha, \beta$ の变形ハターンに対寸る影留として, ここでは $2 a=x_{2}-x_{1}$, すなわセシェル内面に压縮応力が 作用している距離のロール閵隔に対する割合で詊価しよ う。この值は， $\alpha$ には無威係で $\beta$ のみによつてきまる. (付録参照). これをFig. 7 に示す. $\beta=0$ (クリーブ無 し) の時 $1 / \sqrt{ } 2, \beta=1$ (粗弾性と等価) の時 $1 / \sqrt{ } 3$ で ある。熱閏鋼の渮介は $\beta=0.1 \sim 0.5^{15) 18) 19)}$ の程度であ ろらから, $2 a=0.61 \sim 0.66$ であり, 変形の基準点は材質 にはあまり依存しないことがわかる.

\section{$3 \cdot 2$ 変形の大きさと材質パラメータの関係}

変形の大きさは 1 回の曲げで生ずる曲率変化 $\varepsilon=\mid \Delta$ $K_{\mathrm{I}}\left(x_{2}\right)|=| \Delta K\left(x_{1}\right) \mid$ で呼価できる. この解は次式で 与えられる。(計算省略)

$$
\varepsilon=\left(\begin{array}{cc}
V \pi(\alpha+\beta) & \Gamma(1 / \beta) \\
\beta\left(1+\frac{\beta}{2}\right) & \Gamma(1 / \beta+1 / 2)
\end{array}\right)^{\beta+\beta}\left(\frac{a^{2}}{2}\right)^{\alpha+\beta}
$$

ここに $\Gamma$ はガンマ関数を示す.

これから実際の歪みを計算するためには，高温鋼の応 力, 奀み関係を正確に知る必要があるが，Fig. 8 には $\beta=0.3$ として， $\alpha$ を種々変えてシェル内面の歪み $\varepsilon を$ 求めた結果を示す。ただし， $\alpha$ を変える場合，当社での $1000{ }^{\circ} \mathrm{C}$ 鋼材の測定結果より, $\varepsilon=0.0083, \varepsilon=0.000926$ $\mathrm{s}^{-1}$ の時の応力が $1.41 \mathrm{~kg} / \mathrm{mm}^{2}$ となるよらにした. シ ェル内温度は簡便のため $1000^{\circ} \mathrm{C}$ 一定とした.

この図より，ほぼ $\alpha$ の值によって，バルジング歪みの 推定値は大きく異なることがわかる.これは $\alpha$ の值によ つて, 上述した条件での応力は一定であるが，実際に生 じる歪みに対匛する変形応力が大きく異なるためであつ て，バルジング歪みの定量的な評価のためには，熱間鋼 の変形応力の推定が極めて重要であることがわかる.

\section{4. 結論}

速続錈造䧟程で生ずるバルジング変形を，2次元の定 常曲げ変形として扱う理論モデルを提出した。この結 果，次のことがわかつた。

（1）変形パターンは一様に外に膨れるのではなく， 複雑な挙動を示す.

(2) 1 回の曲げで生ずる曲率変化量で評価される変 形量の大きさは，ロール間隔の中心点で計測したふくれ 量より大きい.

(3) 材料の応力・歪又関係におけるパラメータのと り方が計算結果に大きく影響する.

ロール間に括けるシェル形状の精密な計測手法の開発 と, 高温鋼材の変形挙動の研究が期待される.

附録 $2 a$ が $\alpha$ に無関係であることの証明

（E2）を変形する。（バーは省略）

$$
\begin{aligned}
& \lrcorner^{\alpha / \beta} \frac{d J K}{d x}=M^{1 / \beta} \\
& \begin{array}{l}
\Delta K^{\alpha \beta+1} \\
\alpha / \beta+1
\end{array}=\int_{x_{0}}^{x} M^{1 / \beta} d x\left(\text { ただし } x=x_{0} \text { の時 } \Delta K=0\right) \\
& \therefore J K=\gamma^{1 / \gamma}\left[\int_{x_{0}}^{x} M^{1 / \beta} d x\right]^{1 / \gamma} \\
& \text { ここに } \gamma=\alpha / \beta+1 \text { とおいた }
\end{aligned}
$$

これより 


$$
\begin{aligned}
& \Delta K_{\mathrm{I}}\left(x_{2}\right)=\gamma^{1 / \gamma}\left[\int_{x_{1}}^{x_{2}} M^{1 / \beta} d x\right]^{1 / \gamma} \\
& \Delta K_{\mathrm{II}}\left(x_{1}\right)=\gamma^{1 / \gamma}\left[\int_{0}^{x_{1}} M^{1 / \beta} d x+\int_{x_{2}}^{1} M^{1 / \beta} d x\right]^{1 / \gamma}
\end{aligned}
$$

だから（E3）第 2 式より

$\int_{x_{1}}^{x_{2}} M^{1 / \beta} d x=\int_{0}^{x_{1}} M^{1 / \beta} d x+\int_{x_{2}}^{1} M^{1 / \beta} d x=2 \int_{0}^{x_{1}} M^{1 / \beta} d x$

と表せる.この式を $a$ に関して解き, 変形の基準点 $x_{1}$ $(=1 / 2-a)$ および $x_{2}(=1 / 2+a)$ を求めるわけであるが, (2)式中のパラメータは $\beta$ だけである.ゆえに $a$ の值 は, 従つて変形の基準点の位置は $\beta$ の沈つて決ま る.

\section{文献}

1) 川和宵穂, 佐滕秀樹, 宮原 垫, 小行野敬之, 根 本秀太郎：鉄と鋼，60(1974), p. 486

2) 森 久: 鉄と鋼, 60 (1974), p. 784

3 ) 熊井浩, 浅野鋼一, 大橋徹虾, 野村悦夫, 藤井 博務：鉄と龬，60 (1974)，p. 894

4) 渖石昭吾, 小舞忠信, 野呂克彦, 秋明站博：鉄と 鋼，60 (1974)，p. 915

5 ) 井上俊朗, 小舞忠信, 新見英俊, 斉滕㤟一, 細㐜 靖彦：鉄と鋼，60 (1974)，A 103

6 ) 藤井博務, 大橋徹郎, 広本健：鉄と鎆，62 (1976), p. 1813
7 ）仅町健一，江見俊彦：鉄と鋼，63(1977)， p. 1296

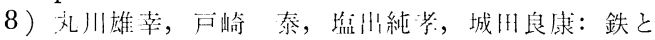
鋼, 61 (1975), S 127

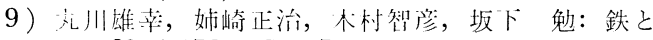
龬，62 (1976), S 107

10）石黑守幸，兑原守，半明正之，内閔繁学，内堀 秀賉：鉄々鋼，62 (1976), S 130

11) K. Wunnenberg: Stahl u. Eisen, 98 (1978), p. 254

12) B. H. Knell: Steel Times, 18 (1967), p. 189

13) R. G. Blossey: Proc. Symp. Continuous Casting, AIME Annual Meeting, Chicago (1973), p. 141

14) K. A. Tekete: Radex Randsh., (1974), p. 135

15) $A$. Palmaers and $A$. Etienne: "Coulee et Solidification de lacier" Rapport Final, Annexe N, Couvertion CCE/CRM, 6210-50 /2/201 Liege, (1977)

16) $K$. Miyazawa and Schwertfeger: Ironma king and Steelmaking (1977), p. 68

17）压延理論とその忘用（日本鉄鋼協会緗）（1969）, p. 124 [誠父堂新光神: ]

18) 作井誠太，声井抔：鉄と龬，63 (1977), p. 285

19) P.J. Wray: Metall. Trans., 7A, (1976) p. 1621 